\title{
Políticas públicas de acessibilidade no ensino superior: implicações na educação do aluno com deficiência ${ }^{1}$
}

\author{
Waléria Henrique dos Santos Leonel ${ }^{2}$ \\ Nilza Sanches Tessaro Leonardo ${ }^{3}$ \\ Raquel de Araújo Bomfim Garcia ${ }^{4}$
}

\section{Introdução}

O tema acessibilidade tem suscitado muitas discussóes na atualidade, sendo respaldada pelas políticas públicas e provocando mudanças no sistema educacional brasileiro. $\mathrm{O}$ ensino superior é uma das modalidades na qual existem poucas pesquisas e discussões referentes a esta temática. No que diz respeito à legislação brasileira, é assegurado a todos o direito à educação, este por sua vez garante náo só o acesso, mas também a permanência do aluno na escola, considerando suas especificidades.

1 Pesquisa vinculada ao projeto em rede "Acessibilidade no Ensino Superior", da Faculdade de Filosofia e Ciências da Universidade Estadual Paulista (FFC-Unesp), Marília/ SP, financiada pelo Programa Observatório da Educação (Obeduc), da Coordenação de Aperfeiçoamento de Pessoal de Nível Superior (Capes) - Edital n. 49/2012.

2 UEL - Universidade Estadual de Maringá. Programa de Pós-Graduação em Psicologia. Maringá - Paraná - Brasil. Mestranda. Bolsista Obeduc/Capes.

waleriahleonel@gmail.com

3 UEL - Universidade Estadual de Maringá. Programa de Pós-Graduação em Psicologia. Maringá - Paraná - Brasil. Pesquisadora do projeto em rede "Acessibilidade no Ensino Superior" (Obeduc/Capes).nilza_sanches@yahoo.com

4 UEL - Universidade Estadual de Maringá. Programa de Pós-Graduação em Psicologia. Maringá - Paraná - Brasil. Mestranda. Bolsista Obeduc/Capes.

pesquisacessibilidade@gmail.com 
Diante desta realidade, o presente artigo visa contribuir para tal discussão e, para tanto, estabeleceu como objetivos fazer um levantamento sobre as legislaçóes brasileiras e documentos internacionais que tratam a temática da acessibilidade e realizar o mapeamento dos alunos que apresentam deficiência, matriculados em uma universidade pública do Estado do Paraná, buscando averiguar se as políticas públicas, de fato, estão se efetivando.

O estudo em questâo faz parte de um projeto de pesquisa de maior abrangência, intitulado "Acessibilidade no Ensino Superior: da análise das políticas públicas educacionais ao desenvolvimento de mídias instrumentais sobre deficiência e inclusão", financiado pelo Programa Observatório da Educação (Edital/Capes n. 49/2012). O mesmo vem sendo desenvolvido em parceria com programas de pós-graduação de universidades brasileiras estaduais e federais, dentre elas, a universidade pesquisada.

\section{Acessibilidade da pessoa com deficiência no ensino superior: analisando as políticas públicas}

No contexto da educação especial, quanto à acessibilidade do aluno com deficiência e ou necessidades educacionais especiais no ensino superior, a realidade atual evidencia um distanciamento ao acesso a esse nível de ensino; sendo poucos os que conseguem ingressar e estes, em sua formação acadêmica, se deparam com muitas barreiras, delineando a realidade do ensino brasileiro (SIMIONATO, 2011). A busca pelo êxito de uma educação que, de fato, seja inclusiva, conta com o respaldo legal e aponta para possibilidades a serem discutidas a fim de viabilizar o acesso ao ensino para todos os alunos com Necessidades Educativas Especiais (NEE) e, com isso, uma sociedade mais igualitária.

Nesse sentido, o Brasil sofreu influência de países americanos e europeus, construindo sua trajetória em prol dos que apresentam NEE (MAZZOTA, 1998). Dessa forma, trazer alguns documentos históricos e atuais torna-se necessário para a análise da realidade da educação especial no Ensino Superior.

Destacamos que os documentos internacionais que exerceram influência sobre o contexto educacional brasileiro foram, principalmente, a Conferência Mundial de Educação Para Todos (ONU, 1990) e a Conferência Mundial sobre Necessidades Especiais: Acesso e Qualidade (1994), realizada na Espanha, na qual foi aprovada a Declaração de Salamanca. Além desses documentos, também tiveram influência numerosos documentos nacionais, como decretos e leis federais, estaduais e municipais, dentre os quais, que merece especial destaque, a Constituição Federal de 1988, cujo importante princípio sobre o ensino está descrito no art. 206, inciso I: "igualdade de condições de acesso e permanência na escola"; ademais, garante o direito à educação para todos sem distinção (BRASIL, 1988). 
Sobre esta discussão, outra lei de suma importância é a LDB 9.394/1996, que prevê a acessibilidade aos alunos com NEE "por meio de adaptaçóes curriculares, com estratégias de ensino diversificadas e processos de avaliação diferenciados" (SILVA, 2012, p.36). De acordo com essa autora, tal lei evidencia a responsabilidade das instituiçôes de ensino e seu dever de realizar as adequaçóes necessárias para garantir aos alunos com NEE condiçóes de aprender e se desenvolver conforme suas particularidades; responsabilidade que se aplica a todos os níveis de ensino.

Assim, por meio da legislação vigente, o Brasil vem delineando açóes de forma que a Educação Especial, pouco a pouco, ganha relevância com a educação inclusiva, e, segundo os documentos oficiais, esta é entendida como uma modalidade destinada aos alunos com NEE em todos os níveis de ensino, do básico ao superior (SIMIONATO, 2011).

Segundo Mendonça (2012), a Política Nacional de Educação Especial na Perspectiva da Educação Inclusiva, do Ministério da Educação e Cultura (MEC), de 2008, define os alunos com NEE como aqueles que apresentam deficiências, transtornos globais de desenvolvimento e altas habilidades/superdotação. Para esse público, assim como para os que apresentam transtornos funcionais específicos, ocorre a articulação entre a Educação Especial e o ensino comum, visando atender às especificidades de cada aluno.

Assim, a Política Nacional de Educação Especial na Perspectiva da Educação Inclusiva tem como objetivo assegurar a inclusão escolar aos alunos com:

Deficiência, transtornos globais do desenvolvimento e altas habilidades/superdotaçáo, orientando os sistemas de ensino para garantir: acesso ao ensino regular, com participação, aprendizagem e continuidade nos níveis mais elevados do ensino; transversalidade da modalidade de educação especial, desde a educação infantil até a educação superior; oferta de atendimento educacional especializado; formaçáo de professores para o atendimento educacional especializado e demais profissionais da educação para a inclusão; participação da família e da comunidade, acessibilidade arquitetônicas nos transportes, nos mobiliários, nas comunicaçôes e informação; e articulação intersetorial na implementação das políticas públicas. (BRASIL, 2010)

Podemos dizer ainda que as políticas no campo da educação inclusiva assinalam as lutas e conquistas ocorridas nas últimas décadas. Os dados estatísticos do Censo Escolar $/ 2006^{5}$ evidenciam o aumento gradativo nas matriculas de alunos com NEE no ensino comum da Educação Básica, abalizando que, neste

5 Os dados estatísticos do Censo Escolar/2006 podem ser encontrados em Brasil (2010). Mendonça (2012, p.168) afirma que, em relação às matriculas de alunos com NEE nas Instituiçốes de Ensino Superior (IES), o Censo Escolar/2006 aponta que, "entre 2003 e 2005 o número de alunos passou de 5.078 para 11.999 . No entanto o número é considerado baixo, assinalando para o fortalecimento da exclusão nesse nível de ensino, e ainda a necessidade de consolidar as políticas de acessibilidade nas IES”. 
nível, a inclusão escolar, em termos de acesso, vem acontecendo, mesmo que de forma tímida; porém, segundo Rambo (2011), em relação ao Ensino Superior, ainda nos deparamos com pouca ênfase política e resultados pouco satisfatórios. Isto denota que os desafios da educaçáo especial, na perspectiva inclusiva, vão além dos que se fazem conhecidos, pois, conforme destacam as leis, as pessoas com alguma NEE têm o direito ao ensino do básico ao superior. Esse ideal ainda está distante, sobretudo no que se refere aos alunos com deficiência intelectual.

Assim sendo, podemos afirmar que a educação especial, numa perspectiva inclusiva, não se constitui apenas de leis, mas muito acima destas deve estar o comprometimento com a pessoa que apresenta NEE. "Infelizmente, necessitamos de documentos oficiais para assegurar os direitos dessas pessoas, documentos, aliás, que não envolvem mudança de concepçôes nem concretização do processo inclusivo" (RAMBO, 2011, p.68).

Em termos de legislação, encontramos documentos oficiais, internacionais e nacionais, que vêm orientando a trajetória da educação especial, na perspectiva inclusiva, em todos os níveis de ensino, inclusive no contexto do Ensino Superior. Assim, para se avançar na educação especial, neste panorama, pensando em proposições que levem, de fato, à consolidação das leis, faz-se importante, em um primeiro momento, conhecer melhor os documentos que regem o sistema educacional brasileiro.

Neste sentido, merece destaque a Portaria do Ministério da Educação n. 3.284, de novembro de 2003, considerando o disposto na Lei n. 9.131, de 24 de novembro de 1995, na Lei n. 9.394, de 20 de dezembro de 1996, e no Decreto n. 2.306, de 19 de agosto de 1997, que assegura aos portadores de deficiência física e sensorial condiçóes básicas de acesso ao Ensino Superior, de mobilidade e de utilização de equipamentos e instalaçôes das instituiçôes de ensino, que em seu art. $1^{\mathrm{o}}$ resolve:

Determinar que sejam incluídos nos instrumentos destinados a avaliar as condiçóes de oferta de cursos superiores, para fins de sua autorização e reconhecimento e de credenciamento de instituiçóes de Ensino Superior, bem como para sua renovação, conforme as normas em vigor, requisitos de acessibilidade de pessoas portadoras de necessidades especiais. (BRASIL, 2003)

Ainda em relação aos documentos legais, referentes à educação especial na perspectiva inclusiva, o Decreto n. 3.298, de 20 de dezembro de 1999, que regulamenta a Lei n. 7.853, de 24 de outubro de 1989, esclarece a definiçáo de deficiência, deficiência permanente e incapacidade, como também diz respeito às adaptaçóes essenciais para o processo ensino-aprendizagem e desenvolvimento do aluno. $\mathrm{O}$ art. 27 desse decreto coloca como atribuição das IES a oferta "de provas e os apoios necessários, previamente solicitados pelo aluno portador de deficiência, 
inclusive tempo adicional para realização das provas, conforme as características da deficiência” (Decreto n. 3.269/1999).

Nesse sentido, Simionato (2011) aponta que o MEC determinou pela Portaria Ministerial n. 1.851, de 27 de dezembro de 1999, que todas as IES do Brasil definam e gerem as condiçóes de acessibilidade aos alunos com NEE, exigindo assim transformaçóes no ambiente acadêmico que assegurem o atendimento a todos, em consonância com as legislaçóes.

Em relação à acessibilidade da pessoa que apresenta algum tipo de deficiência ou mobilidade reduzida, o Brasil conta com a Lei n. 10.098, de 19 de dezembro 2000 , que em seu art. $1^{\circ}$ estabelece a supressão de barreiras e de obstáculos nas vias e espaços públicos, no mobiliário urbano, na construção e reforma de edifícios e nos meios de transporte e de comunicação.

Para fins de compreensão, a Lei n. 10.098/2000, regulamentada pelo Decreto n. 5.296, de 2 de dezembro de 2004, assim define, em seu art. $8^{\circ}$, o que se deve entender por acessibilidade e as barreiras que a impedem ou dificultam:

I - acessibilidade: condiçáo para utilização, com segurança e autonomia, total ou assistida, dos espaços, mobiliários e equipamentos urbanos, das edificaçóes, dos serviços de transporte e dos dispositivos, sistemas e meios de comunicação e informação, por pessoa portadora de deficiência ou com mobilidade reduzida; II - barreiras: qualquer entrave ou obstáculo que limite ou impeça o acesso, a liberdade de movimento, a circulação com segurança e a possibilidade de as pessoas se comunicarem ou terem acesso à informação, classificadas em: a) barreiras urbanísticas: as existentes nas vias públicas e nos espaços de uso público; b) barreiras nas edificaçôes: as existentes no entorno e interior das edificaçóes de uso público e coletivo e no entorno e nas áreas internas de uso comum nas edificaçōes de uso privado multifamiliar; c) barreiras nos transportes: as existentes nos serviços de transportes; d) barreiras nas comunicaçóes e informaçóes: qualquer entrave ou obstáculo que dificulte ou impossibilite a expressão ou o recebimento de mensagens por intermédio dos dispositivos, meios ou sistemas de comunicação, sejam ou não de massa, bem como aqueles que dificultem ou impossibilitem o acesso à informação. (BRASIL, 2004)

De acordo com essa lei, pudemos identificar que as barreiras físicas ao acesso e permanência de alunos deficientes no Ensino Superior vêm sendo tratadas no campo da legalidade, buscando-se minimizar os desafios impostos pela falta de condiçôes básicas exigidas para atender aos direitos desses alunos. Porém, foi possível verificar também que as barreiras intelectuais vivenciadas por esses alunos, nesta trajetória escolar, são pouco destacadas, configurando-se como o maior desafio para as IES. Essa legislação nos inspira a pensar o insucesso escolar nesse nível de ensino, o qual ainda é um campo real que necessita de pesquisas na busca por eliminar esses tipos de barreiras, tendo-se em vista que estas ainda são as que fortalecem a exclusão dos alunos com deficiência dos bancos acadêmicos. 
No art. 24 da referida lei, fica determinado que os:

estabelecimentos de ensino de qualquer nível, etapa ou modalidade, públicos ou privados, proporcionarão condiçôes de acesso e utilização de todos os seus ambientes ou compartimentos para pessoas portadoras de deficiência ou com mobilidade reduzida, inclusive salas de aula, bibliotecas, auditórios, ginásios e instalaçôes desportivas, laboratórios, áreas de lazer e sanitários. (BRASIL, 2004)

A partir desta determinação, fica estabelecido que as IES têm de cumprir as medidas dispostas na lei para que possam obter a autorização para funcionamento e abertura ou renovaçáo de curso (BRASIL, 2004).

Outra lei que demarca mudanças nas IES, no que diz respeito aos direitos dos alunos com NEE, é a n. 10.172, de 9 de janeiro de 2001, que aprovou o Plano Nacional de Educaçáo. Esta traz como diretriz a proposta de plena integraçáo da pessoa com NEE em todas as áreas da sociedade, com a garantia do "[...] direito à educação, comum a todas as pessoas, e o direito de receber essa educação sempre que possível junto com as demais pessoas nas escolas 'regulares"” (BRASIL, 2006).

De acordo com Simionato (2011), a educação especial, na perspectiva inclusiva, muito mais que por leis, clama por uma transformação das práticas sociais vivenciadas no país, em busca de alcançar uma sociedade democrática que luta pela igualdade de todos, conforme prevê a legislação brasileira.

Isto nos permite afirmar que a educação especial no Ensino Superior se configura como um desafio, pois, como aponta Rambo (2011, p.67), os alunos com necessidades especiais nesse nível de ensino

continuam encontrando muitas dificuldades, não por incapacidade ou limitaçôes individuais, mas por limitaçóes impostas pelo social. O fato de os direitos das pessoas com deficiência serem assegurados legalmente não garante que esses direitos sejam concretizados efetivamente; para que o sejam é preciso uma mudança de comportamento social.

Tal fato pode ser evidenciado quando tomamos como referência a matrícula de alunos com deficiência numa IES do interior do Paraná, a Universidade Estadual de Maringá (UEM), tendo como base as informaçóes concedidas pelo Diretório de Assuntos Acadêmicos (DAA), pautado na ficha de matrícula do acadêmico. Nesta, o mesmo declara, dentre outros aspectos, se possui alguma deficiência e de qual natureza (auditiva, física, intelectual, múltipla, outras e visual - inclui-se visão parcial e visual total). 


\section{Mapeamento dos alunos com deficiência no ensino superior: compreendendo a acessibilidade}

Os dados coletados nos mostram, como pode ser notado no Gráfico 1, que alunos com algum tipo de deficiência têm adentrado nesta IES. Todavia, há de se considerar que isto não é um fato para aqueles que possuem deficiência intelectual, pois náo há alunos com este tipo de deficiência matriculado. Também consideramos importante destacar que o maior número de alunos, isto é, 54\% dos que se declararam como deficientes, são aqueles que apresentam um comprometimento parcial da visão, e que necessitam apenas do uso de óculos para correção.

Os alunos que possuem deficiência visual total e que necessitam de atendimento educacional especializados correspondem a apenas 5\% dos que têm deficiência. $\mathrm{O}$ mesmo ocorre com aqueles que possuem deficiência auditiva, os quais possuem um percentual baixo nesta IES, apenas de $6 \%$.

Destacamos que o percentual mais alto foi para alunos com deficiência física, com $16 \%$. Este resultado aponta para o fato de que, nesta IES, são os alunos com deficiência física os que mais têm conseguindo chegar neste nível educacional, assim derrubando a seletividade que acontece durante a Educação Básica, bem como a barreira do vestibular.

Tais resultados mostram que entre as deficiências, há aquelas que são mais excluídas no Ensino Superior, como, por exemplo, a intelectual, seguida da visual. Isto, portanto, suscita alguns questionamentos: por que são os deficientes físicos os que mais conseguem chegar nesta IES? Por que são os deficientes intelectuais os que menos chegam à IES? Certamente, as respostas a esses questionamentos envolvem a compreensão de vários aspectos, dentro os quais destacamos as concepções que prevalecem sobre as deficiências na sociedade, bem como as políticas públicas em educação, sobretudo da educação especial no Brasil.

Outro aspecto relevante é a formação destes alunos na Educação Básica, ou seja, como esta tem trabalhado com a diversidade, garantindo aos alunos com deficiência a aprendizagem e desenvolvimento. É notório que nem todos os alunos têm avançado aos níveis superiores de desenvolvimento, mantendo-se excluídos do acesso ao conhecimento científico. Sobre esses aspectos, Meira (2011, p.74) revela que a exclusão do sistema educacional, no momento, apresenta-se de forma diferente, "mais sutil, embora não menos violento: a permanência nas escolas por longos períodos de tempo de crianças e jovens que nunca chegam a se apropriar de fato dos conteúdos escolares". A autora ainda enfatiza a facilitação nos critérios avaliativos, fazendo com que o aluno apenas passe e conclua sua escolaridade. Entendemos que este seja um dos fatores mais relevantes na não inserção de pessoas com deficiência no Ensino Superior, visto que os critérios do vestibular estão pautados na aquisição de conhecimentos científicos adquiridos ao longo da Educação Básica. 
Gráfico 1. Número de alunos com deficiência matriculados na UEM em 2014 (em \%)

\begin{tabular}{lc}
\hline DEF. VISUAL PARCIAL & $54 \%$ \\
\hline \hline DEF. FÍSICA & $16 \%$ \\
\hline \hline AUDITIVA & $6 \%$ \\
\hline \hline DEF. VISUAL TOTAL & $5 \%$ \\
\hline \hline MÚLTIPLA & $1 \%$ \\
\hline \hline DEF. INTELECTUAL & $0 \%$ \\
\hline \hline
\end{tabular}

Fonte: Diretório de Assuntos Acadêmicos (DAA), UEM.

Considerando essa IES, Simionato (2011, p.307) expóe que, no ano de 1998, foi instituída a Resolução n. 032/97 (CEP), "que regulamenta os procedimentos para o ingresso na UEM de pessoas portadoras de deficiência, através do concurso vestibular". Podemos observar a partir dos dados obtidos que de fato vem ocorrendo, mesmo que em número reduzido, o ingresso de pessoas com deficiência nesta IES.

Esta IES conta com um programa institucional, que está em funcionamento desde 1994, chamado Programa Interdisciplinar de Pesquisa e Apoio à Excepcionalidade (Propae), cujos objetivos consistem em diagnosticar, avaliar e dar atendimento específico à excepcionalidade e desenvolver apoio psicopedagógico, tecnologias e metodologias adequadas. Pudemos identificar que esta universidade tem oferecido as adaptaçóes necessárias durante o processo do vestibular, bem como tem dado suporte a alunos com deficiência que frequentam a instituição. $\mathrm{O}$ trabalho desenvolvido pelo Propae demanda tempo, pois requer mudanças de atitude e planejamento e estas devem abranger a comunidade como um todo, tanto familiar quanto institucional (SIMIONATO, 2011). No entanto, é uma iniciativa que tem possibilitado condiçóes de acessibilidade aos alunos que procuram pelo seu serviço.

Manzini (2006 apud Morejón, 2009) contribui expondo que a acessibilidade não se restringe a dar oportunidade de participação para as pessoas com deficiência em diferentes contextos, mas faz-se necessária mudanças de atitudes, de comportamentos e da organização das atividades humanas a fim de diminuir o impacto de uma deficiência. Como vimos anteriormente, as políticas públicas já asseguram os direitos, mas ainda existem muitas barreiras tanto arquitetônicas quanto sociais que dificultam o pleno exercício da cidadania.

Mesmo diante destes fatos, reconhecemos que a realidade da acessibilidade de pessoas com deficiência e/ou mobilidade reduzida é pouco relevante, quando comparado ao número de alunos sem deficiência matriculados nesta IES. Esta 
instituição tem 23.186 alunos matriculados; considerando os alunos que possuem deficiência visual parcial, que representam 54\% dos alunos com deficiência, ainda assim teremos um percentual pouco expressivo em relação ao total de alunos, isto é, de $1,38 \%$. Se retiramos esses alunos do cálculo de alunos com deficiência, teremos um percentual ainda mais baixo de alunos com deficiência em relação ao total, isto é, $0,64 \%$, como revela o Gráfico 2.

Gráfico 2. Acadêmicos matriculados na UEM, em 2014

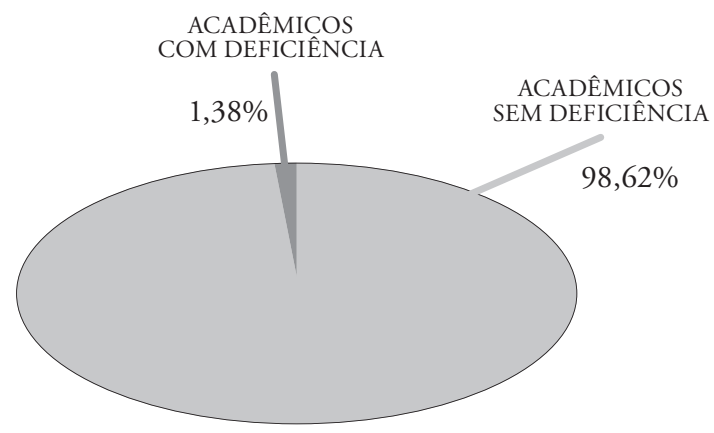

Fonte: Diretório de Assuntos Acadêmicos (DAA), UEM.

Então, podemos afirmar que esta IES ainda não é acessível a todos, sobretudo àqueles com deficiência. Sobre esse aspecto, Chaui (2001, p.35) nos informa que "a universidade é uma instituição social. Isso significa que ela realiza e exprime de modo determinado a sociedade de que faz parte. Não é uma realidade separada e sim uma expressão historicamente determinada de uma sociedade determinada". Com isso, percebemos que a acessibilidade ainda náo faz parte desta realidade.

\section{Considerações finais}

Em consonância com o que está sendo discutido neste texto, Simionato (2011) assinala que atualmente o pequeno número de alunos que ingressam nas IES é reflexo de uma educação básica e de nível médio precária, que não prepara o aluno com NEE para o acesso, permanência e conclusão de sua formação acadêmica. Afirma a autora:

Sem desmerecer tentativas isoladas bem-sucedidas, posso afirmar que a escola nos diversos níveis de ensino carece ainda de uma compreensão da deficiência como um fenômeno biopsicossocial que permita superar a distância e a contradiçáo entre o discurso e a prática, eliminando barreiras didáticos-pedagógicas ao pleno acesso ao conhecimento humano acumulado. (SIMIONATO, 2011, p.339) 
Desse modo, temos que as políticas públicas que versam sobre a educação, em específico a educação especial na perspectiva inclusiva, representaram avanços no sistema educacional, pois têm possibilitado e garantido o acesso de pessoas com NEE aos bancos escolares na Educação Básica; porém, a inserção do aluno deficiente no Ensino Superior ainda representa desafios a serem vencidos, especialmente no que se refere ao aluno deficiente intelectual, visto que, nesse nível de ensino, tal temática é ainda recente e provoca discussóes e indagaçóes na sociedade atual.

Nosso estudo apontou que há poucas pesquisas que tratam da temática do acesso e da permanência do deficiente no nível superior de ensino. Entretanto, identificamos que há algumas que se destacam e contribuem para as discussóes nesta área. Este, portanto, constitui-se em um campo fértil que precisa ser explorado, pois são muitas as contribuições que devem ser dadas à ciência, à sociedade, e em específico, às pessoas com deficiência. Pois estamos diante de muitas inquietaçóes, sobretudo em relação ao aluno com deficiência intelectual, o qual, apesar das leis e mudanças na educação, carrega o estigma de incapacidade. Esse aluno é o que mais tem vivenciando em seu cotidiano barreiras que vão muito além das definidas por lei, ou seja, a impossibilidade de construir com autonomia uma vida independente. Neste contexto, a escola e o ensino por ela ofertado são os meios para este indivíduo se desenvolver, isto é, construir-se enquanto ser social.

Para Vigotski (2011, p.869), "o desenvolvimento cultural é a principal esfera em que é possível compensar a deficiência. Onde não é possível avançar no desenvolvimento orgânico, abre-se um caminho sem limites para o desenvolvimento cultural". Para esse autor, faz-se necessário buscar caminhos indiretos quando não é possível por meios diretos. De fato, esse é o papel da educação em todos os níveis de ensino.

Por isso, é pertinente reforçar a necessidade de maiores efetivaçóes no campo das políticas públicas, de investimentos em pesquisas sobre a temática, de discussôes e reflexões acerca das ações que envolvem a educação especial no Ensino Superior, nas quais se busque, a partir da inclusão, a garantia de direitos, a valorização e o respeito ao deficiente, no tentame de superar as dificuldades enfrentadas, atualmente, neste nível de ensino por todos os envolvidos no processo de inclusão, entre eles, os alunos com NEE e, particularmente, os alunos com deficiência intelectual. ${ }^{6}$

6 Reservamos nossos sinceros agradecimentos ao reitor da Universidade Estadual de Maringá (UEM) que nos autorizou a realizar o mapeamento dos alunos com deficiência desta IES, a partir do Diretório de Assuntos Acadêmicos (DAA); como também ao Programa Observatório da Educação (Obeduc), pelo financiamento desta pesquisa (Edital Capes n. 49/2012). 


\section{Referências}

BRASIL. Constituição da República Federativa do Brasil de 1988. Capítulo III. Da Educação. Disponível em: http://www.legjur.com/legislacao/htm/cf8800000001988?gclid=CNrIm678LYCFccw4AodvE4ArA\#i208-00. Acesso em: 29 out. 2014.

BRASIL. Presidência da República. Casa Civil. Decreto n. 3.298, de 1999. Disponível em: http://www.planalto.gov.br/ccivil_03/decreto/d3298.htm. Acesso em: 27 out. 2014.

BRASIL. Ministério da Educação. Portaria Ministerial n. 3.284 de 2003. Disponível em: http://download.inep.gov.br/download//superior/2003/Legislacao/Portaria_3284_2003_ acessibilidade_portadores_deficiencias.pdf. Acesso em: 28 out. 2014.

BRASIL. Presidência da República. Casa Civil. Decreto n. 5.296/2004, 2004. Disponível em: http://www.planalto.gov.br/ccivil_03/_ato2004-2006/2004/decreto/d5296.htm. Acesso em: 27 out. 2014.

BRASIL. Legislação brasileira sobre pessoas portadoras de deficiência de 2006. Brasília: Câmara dos Deputados, Coordenação de Publicações, 2006. Disponível em: http://www. miltonmonti.com.br/arquivos/downloads/legislacao_portadoresdeficiencia.pdf. Acesso em: 19 out. 2014.

BRASIL. Presidência da República. Casa civil. Plano Nacional de Educação. Lei n. 8.035, de 2010. Disponível em: http://www.pne.ufpr.br/?page_id=16. Acesso em: 28 out. 2014.

CHAUI, M. Escritos sobre a universidade. São Paulo: Editora Unesp, 2001.

MAZZOTTA, M. J. S. Educação especial no Brasil: história e políticas públicas. São Paulo: Cortez, 1998.

MEIRA, M. E. M. Incluir para continuar excluindo: a produção da exclusão na educação brasileira à luz da psicologia histórico-cultural. In: FACCI, M. G. D.; MEIRA, M. E. M.; TULESKI, S. C. (Orgs.). A exclusão dos “incluídos": uma crítica da psicologia da educação à patologização e medicalização dos processos educativos. Maringá: Eduem, 2011. p.75-106.

MENDONÇA, F.W. Estrutura e funcionamento da educação básica. Maringá: Centro Universitário de Maringá, Núcleo de Educação à Distância, 2012.

MOREJÓN, K. O acesso e a acessibilidade de pessoas com deficiência no Ensino Superior público no Estado do Rio Grande do Sul. 2009. Tese (Doutorado em Ciências Sociais). Faculdade de Filosofia, Ciências e Letras de Ribeirão Preto, USP. Ribeirão Preto, 2009.

PARANÁ. Secretaria de Estado da Educação (Seed). Diretrizes Curriculares da Educação Especial para a Construção de Currículos Inclusivos. Curitiba, 2006. Disponível em: http://www. nre.seed.pr.gov.br/londrina/arquivos/File/dce_ed_especial(1).pdf. Acesso em: 20 out. 2014.

RAMBO, C. P. A inclusão escolar na perspectiva de alunos com deficiência no Ensino Superior: contribuições da psicologia histórico-cultural. 2011. Dissertação (Mestrado em Psicologia). Programa de Pós-Graduação em Psicologia, Universidade Estadual de Maringá. Maringá, 2011.

SILVA, M. A. M. Atendimento educacional especializado e o processo de inclusão. Maringá: Centro Universitário de Maringá, Núcleo de Educação à Distância, 2012.

SIMIONATO, M. A. W. O deficiente no Ensino Superior: uma reflexão. In: FACCI, M. G. D.; MEIRA, M. E. M.; TULESKI, S. C. (Orgs.). A exclusão dos "incluidos": uma crítica da psicologia da educação à patologização e medicalização dos processos educativos. Maringá: Eduem, 2011. p.299-313.

VIGOTSKI, L. S. A defectologia e o estudo do desenvolvimento e da educação da criança anormal. Educação e Pesquisa, São Paulo, v.37, n.4, p.861-870, dez. 2011. 


\section{Resumo}

Políticas públicas de acessibilidade no ensino superior: implicações na educação do aluno com deficiência

O presente estudo teve por objetivo fazer um levantamento das leis que versam sobre a acessibilidade no ensino superior, e realizar o mapeamento dos alunos que apresentam deficiência matriculados em uma universidade pública do Estado do Paraná. Para tanto, em um primeiro momento, fez-se uma varredura na legislação, buscando as leis que tratam sobre a acessibilidade na educação superior. Na sequência, realizou-se o mapeamento dos alunos matriculados nesta Universidade e, por fim, fez-se a análise das informaçóes obtidas, correlacionando aquelas da legislaçáo com os dados do mapeamento. Os resultados evidenciaram que não basta apenas a existência de leis que tratem a temática para que ocorra a acessibilidade entre as pessoas com deficiência no espaço social e educacional, sobretudo no Ensino Superior. As informaçóes reunidas revelam que, no que se refere à acessibilidade nos espaços universitários, têm chegado alunos com deficiência nesta modalidade de ensino, ainda que em quantidade pouco expressiva. Confirmando, desta forma, que alguns desses alunos têm conseguindo derrubar a seletividade que sucede ainda durante a educaçáo básica. Entretanto, os resultados apontaram também que a universidade náo é uma realidade para a maioria das pessoas com deficiência, mesmo diante das políticas públicas que legitimam esse direito.

Palavras-chave: Acessibilidade. Deficiência. Ensino Superior. Políticas Públicas.

\section{Abstract}

\section{Public Policies on Accessibility in Higher Education:} Implications for the Education of Students with Disabilities

The objective of this study is to survey the laws addressing accessibility in higher education, and to map the students with disabilities enrolled in a public university in the state of Paraná. First, a review of the legislation was done, seeking laws that deal with accessibility in higher education. Following, a mapping of students enrolled in this university, and finally, the analysis of obtained information, correlating legislation and mapping data. The results showed that the existence of laws addressing the issue is not enough to guarantee accessibility to those with disabilities in social and educational space, particularly in higher education. The information gathered shows that, concerning accessibility in university spaces, students with disabilities have reached this level of education, although not in significant numbers. This has been used to promote the idea that some of these students are managing to topple the selectivity that still happens during basic education. However, the results also indicated that the university is not a reality for most people with disabilities, even in the face of public policies that legitimize this right.

Keywords: Accessibility. Disabilities. Higher Education. Public Policy. 